\title{
A CORRIDA ATRÁS DO OBJETO: OS ANTISSUJEITOS ÁTONO E TÔNICO
}

\author{
CHASING THE OBJECT: \\ UNSTRESSED AND TONIC ANTI-SUBJECTS
}

\author{
Carolina TOMASI ${ }^{1}$ \\ USP - Universidade de São Paulo
}

\begin{abstract}
RESUMO: Este artigo verifica como as interrupções na HQ "Futboil", de Luiz Gê, são reguladas. Os estudos de missividade de Zilberberg (2006) observam que, quando o fazer emissivo impera, o percurso do sujeito evolui, a narrativa avança e que, quando o fazer remissivo impera, o antissujeito entra em cena, e o percurso do sujeito sofre uma parada em sua evolução, ficando latente. Trata-se de uma intercalação na narrativa entre a parada (remissividade) e a parada da parada (emissividade). Com base nesse jogo missivo, partimos da proposição de dois tipos de antissujeito: de densidade fraca, átono, que interrompe fracamente o percurso do sujeito, e de densidade forte, tônico, que interrompe fortemente a narrativa, ou, em alguns casos, como é o exemplo do final de "Futboil" (a destruição do balão), que introduz uma parada definitiva, chegando a destruir o próprio objeto almejado. Este último tipo faz paradoxalmente o papel actancial de antissujeito e de sujeito: eles mesmos querem, eles mesmos conseguem e eles mesmos rasgam o balão.
\end{abstract}

PALAVRAS-CHAVE: Semiótica tensiva; HQs; Semiótica visual; Antissujeito.

ABSTRACT: This paper verifies how interruptions are regulated in Luiz Gê's "Futboil" comic story. Zilberberg's missivity studies (2006) that when the emissive making prevails, the route of the subject evolves, the narrative progresses and that when the remissive making reigns, the anti-subject enters the scene, and the route of the subject suffers a stop in its evolution, becoming latent. It is about a merge in the narrative between the stop (remissivity) and the stopping of the stop (emissivity). We examined in comparative terms two comic stories which go along two diverse ways: one of them in remissive dominance, the other in emissive dominance; we found pertinence in the study of anti-subject's function - that is, to derange the "subject $\rightarrow$ object" sequence. If the anti-subject was not present, the subject-object would go to a depletion of the narrative, that is, an absolute harmony. We start by proposing two types of anti-subjects: one of low density, unstressed, which weakly interrupts the path of the subject; another of high density, tonic, which strongly interrupts the narrative or, in some cases, as at the end of "Futboil "(destruction of the balloon), that introduces a final stop, coming to destroy the very desired object. The latter type paradoxically plays the actantial role of anti-subject and subject: the characters themselves want, they themselves achieve and they themselves tear the balloon into pieces.

KEY WORDS: Tensive semiotics; Comic stories; Visual semiotics; Anti-subject.

\footnotetext{
${ }^{1}$ Doutoranda no Programa de Pós-Graduação em Linguística da Universidade de São Paulo, São Paulo, Brasil. É bolsista do CNPq.
} 
Precisamos conceber um mundo que não seja feito apenas de coisas, mas de puras transições.

Merleau-Ponty

\section{Preliminares}

Para analisar como as paradas são reguladas na HQ "Futboil", de Luiz Gê, partimos da proposição de dois tipos de antissujeito ${ }^{2}$ (1) o mais átono, que interrompe fracamente o percurso do sujeito e (2) o mais tônico, que interrompe fortemente a narrativa, ou, em alguns casos, como acontece no final de "Futboil" ("a destruição do balão"), que introduz uma parada definitiva na narrativa, chegando a destruir o próprio objeto almejado.

\section{1 "Futboil" - a corrida cinematográfica atrás do objeto: a regência da emissividade}

"Futboil" tematiza a quebra do cotidiano por um acontecimento inusitado: pessoas que descansavam em casa, que transitavam pelas ruas e calçadas, garotos que jogavam futebol têm seu cotidiano interrompido pela queda de um balão. O acontecimento tem o poder de retirar o sujeito da sua rotina e de deixá-lo exposto e vulnerável aos encantos do objeto (TATIT, 2010, p. 45). O sujeito, antes dono de seu percurso, chega a funcionar como "presa" da atratividade exercida pelo objeto. E, à página 46, Tatit afirma que "justamente por estar mergulhado num universo em que a vida lhe parece incompleta - e, portanto, imperfeita - o sujeito alimenta a espera de um estado pleno, caracterizado por sua fusão com o objeto, como se $[\ldots]$ pudessem constituir um ser integral".

Uma das características das escolhas enunciativas de Luiz Gê é produzir cada enunciado dos quadrinhos como se eles fossem um recorte sobre um movimento de câmera contínuo, distribuído ao longo das páginas de "Futboil", publicada no livro Território de bravos (GÊ, 1993). Os enquadramentos (aproximação e distanciamento) podem ser traduzidos em abertura e em fechamento, categorias semióticas, e não mera focalização de movimento de câmera do cinema, nem mera sequência de imagens de HQs. Para nós, abertura e fechamento são categorias que subentendem a presença tônica ou átona de um antissujeito.

O estudo da missividade nas narrativas (ZILBERBERG, 2006, p. 137; cf. também PIETROFORTE, 2009) permite-nos breve homologação:

\section{Fazer emissivo (a narrativa corre - presença átona do antissujeito)/difusão/distanciamento :: Fazer remissivo (a narrativa para - presença tônica do antissujeito)/concentração/aproximação}

"Futboil" é uma HQ dominantemente de fazer emissivo, o que traduz um bom exemplo do movimento contínuo. Das sete HQs de Território de bravos, ela é a que melhor reproduz o movimento cinematográfico. Esse efeito de cinema é resultado do elevado número de difusões em meio a um número reduzido de quadrinhos remissivos (concentrados). Por intermédio de suas aberturas e emissividade, o enunciatário corre os olhos sobre cada quadrinho, a cada virada de página, numa continuidade que só se esgota ao final da HQ, o que configura um efeito de sétima arte.

\footnotetext{
${ }^{2}$ Essas reflexões têm início em artigo com a parceria de Jean Cristtus Portela, a quem dedico estes escritos e agradeço (cf. PORTELA; TOMASI, 2012).
} 
A aproximação de "Futboil" com o cinema apoia-se particularmente no tratamento que este último dá ao tempo e ao espaço. A narrativa não se ocupa de apresentar o desenrolar dos acontecimentos em uma sequência linear, havendo cortes e saltos que aceleram o percurso do sujeito. O fechamento nessa HQ não é aleatório, mas regulado conforme a abertura: "o uso do close-up, por exemplo, não só tem critérios espaciais como também representa uma fase a ser atingida ou a ser suplantada no desenvolvimento temporal do filme. Num bom filme, os close-ups não são distribuídos de maneira arbitrária e caprichosa" (HAUSER, 2003, p. 971). No último quadrinho, o enunciatário depara com um fechamento máximo que indica a consecução do propósito do destinador. Daí o palhaço surgir como destinador julgador, sancionando negativamente a inabilidade dos sujeitos (atores meninos) que, ao jogarem, em vez de desfrutarem do jogo, destroem o objeto do desejo. Aqui, a vitória configura-se uma derrota (figura 1), uma espécie de vitória de Pirro, ou seja, uma vitória obtida a alto preço, potencialmente acarretadora de prejuízos irreparáveis.

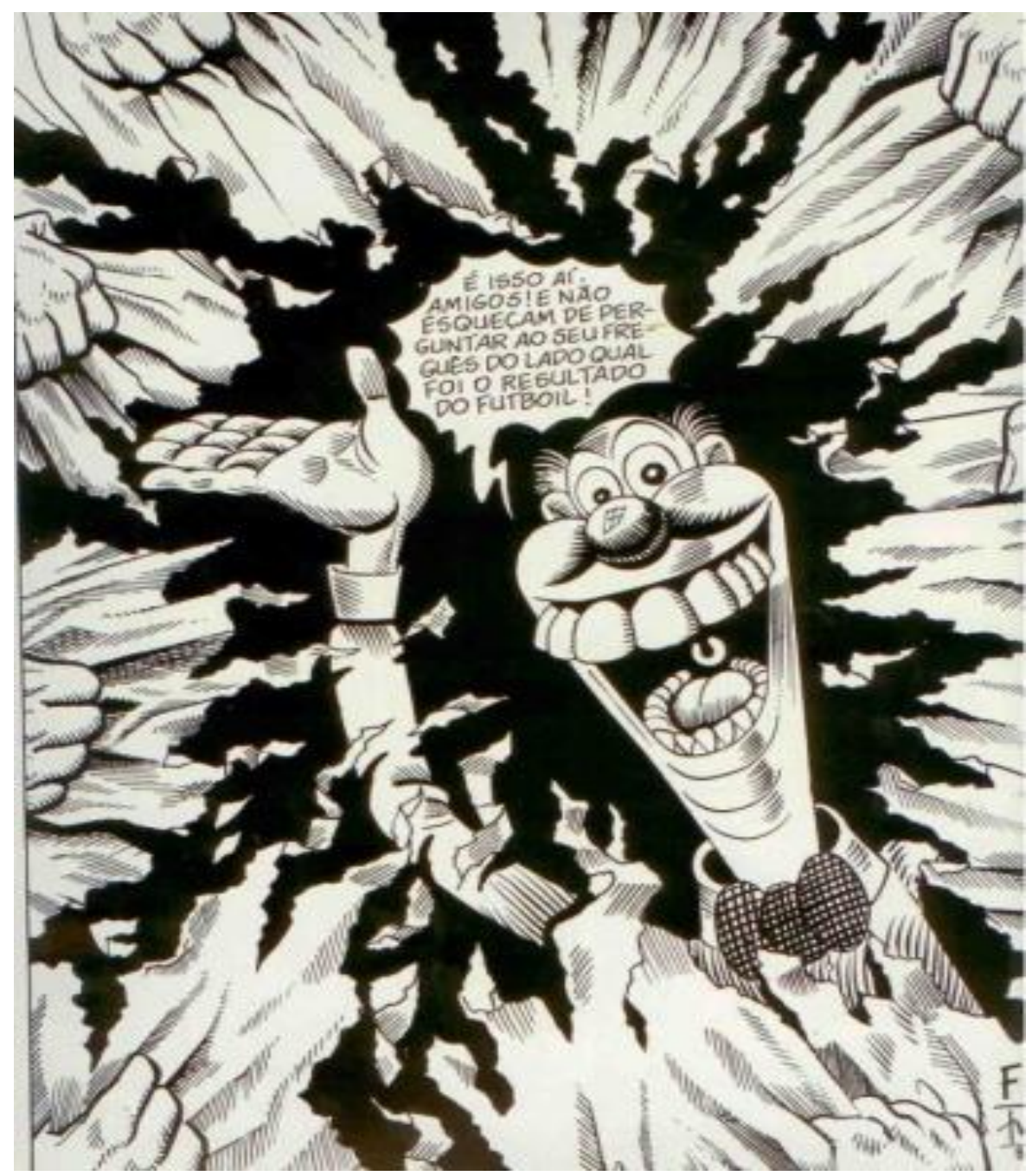

Figura 1

Ao escolher a dominância da difusão (fazer emissivo), o enunciador de "Futboil" opta por apresentar um quadro de ações, verbalizado, configurando a vida cotidiana interrompida pelo aparecimento de um balão. A seguir, apresentamos um breve estudo sobre o antissujeito nas narrativas. 
CASA, Vol.11 n.2, dezembro de 2013

\section{Avanços e paradas em Futboil}

Em relação ao objeto figurativizado discursivamente pelo balão, temos dois tipos de sujeito: o que o repele e o que o quer de qualquer maneira. A parte desinteressada do objeto, em "Futboil", configura na narrativa o antissujeito da parte interessada. Os interessados no balão são meninos que brincam na rua, e os que repelem o balão são adultos, atores mais velhos. Daí que o percurso do sujeito (atores meninos) é interrompido pelo antissujeito (atores mais velhos). Quando o fazer emissivo impera, o percurso do sujeito evolui, a narrativa avança; quando os valores remissivos imperam, o antissujeiro entra em cena, e o percurso do sujeito sofre uma parada em sua evolução, ficando latente; a dominância aqui é emissiva, portanto. Trata-se de um jogo entre a parada (remissividade) e a parada da parada (emissividade) na narrativa.

$\mathrm{Na}$ figura 2, podemos observar no primeiro quadrinho, um fazer emissivo, pois os sujeitos estão em movimento em busca do objeto. $\mathrm{O}$ antissujeito entra em cena figurativizado pela primeira vez na HQ por um cachorro; nesse caso, o antissujeito tem baixa densidade de presença, é átono e, portanto, superado facilmente pelo sujeito (ator menino). No sexto quadrinho da figura também podemos notar a pouca densidade de presença de outro antissujeito, figurativizado por um muro: o ator menino, após ultrapassar o cachorro, o supera facilmente.

Em "Futboil", na medida em que o valor emissivo cresce, o valor remissivo vai se tornando mais sensível, emergindo claramente na HQ sob análise. Até o trigésimo segundo quadrinho, o fazer emissivo é dominante e, no nível discursivo, os garotos correm atrás de um balão, sem grandes obstáculos por parte do antissujeito. A dominância emissiva, o estado de latência de um antissujeito mais tônico e eficaz do que o visto, acaba por fazer irromper valores remissivos no final da narrativa (figura 6). 

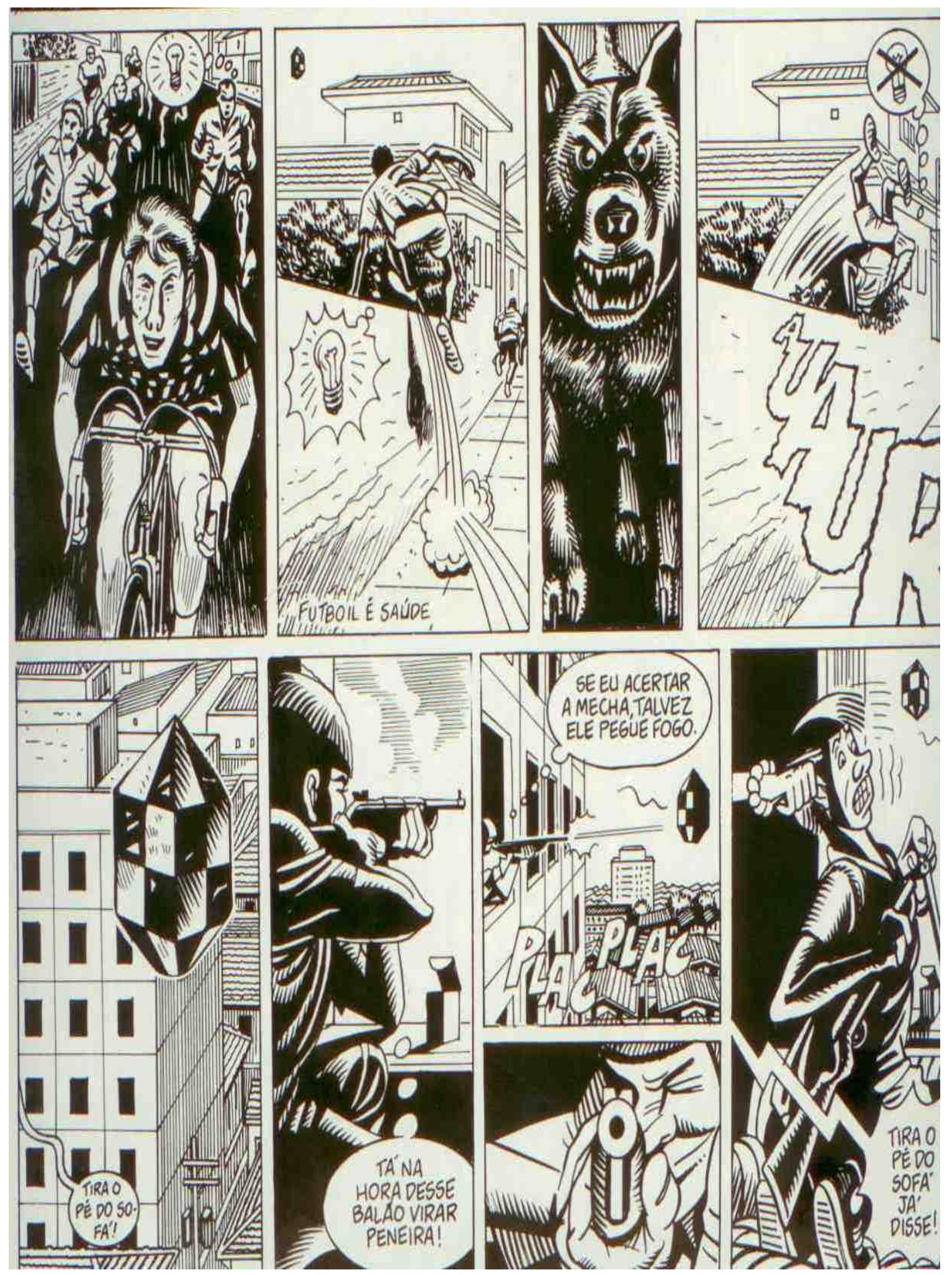

Figura 2 - Antissujeito: figura do cachorro, no terceiro quadrinho, interrompendo momentaneamente a narrativa; no sexto quadrinho, a figura do garoto mostra a aproximação de um antissujeito, que quer arrebentar o balão, mas não consegue; temos, então, uma pequena parada na narrativa. 
Vejamos detidamente nas figuras 3 a 6 a presença do antissujeito na narrativa de "Futboil". Breves análises constam das legendas das figuras.

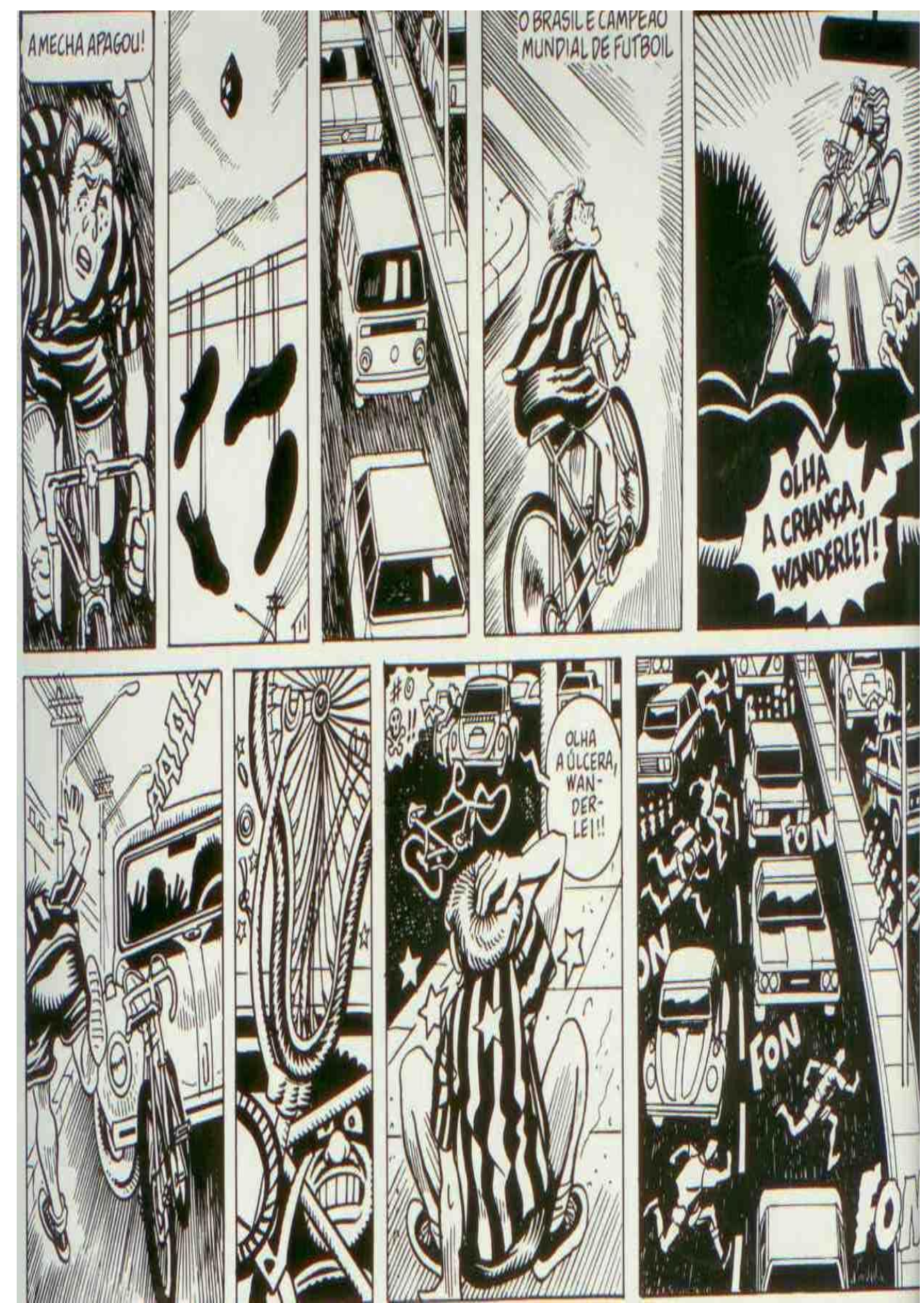

Figura 3 - Antissujeitos: no sexto quadrinho, figura da parada (choque do menino com o carro). Ele cai por um momento (pequena parada): antissujeito ainda átono. 


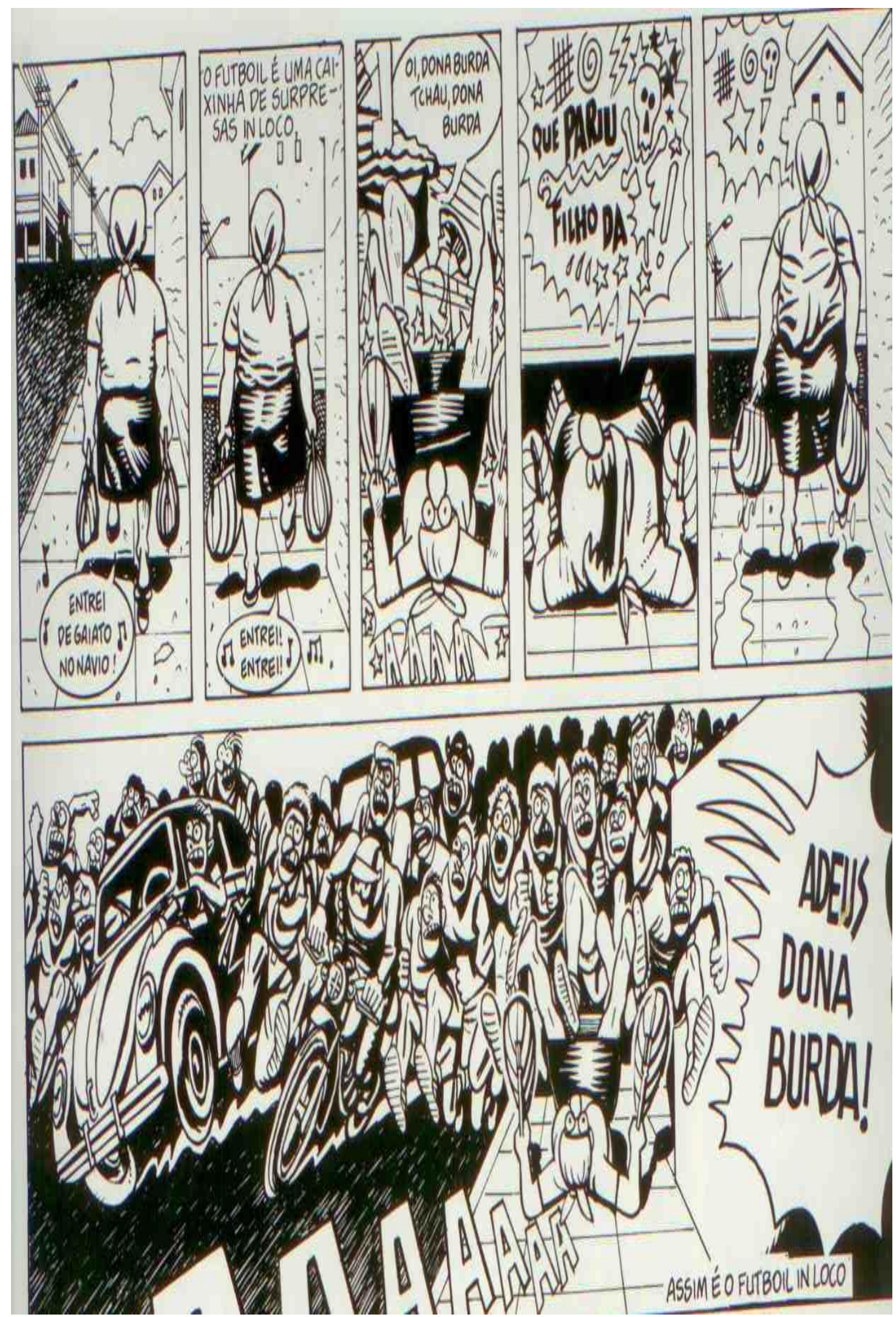

Figura 4 - Antissujeito no terceiro quadrinho: a figura da Dona Burda no caminho dos meninos configura outra pequena parada; todavia, novamente, o antissujeito é superado. Nesse caso, ainda átono. 

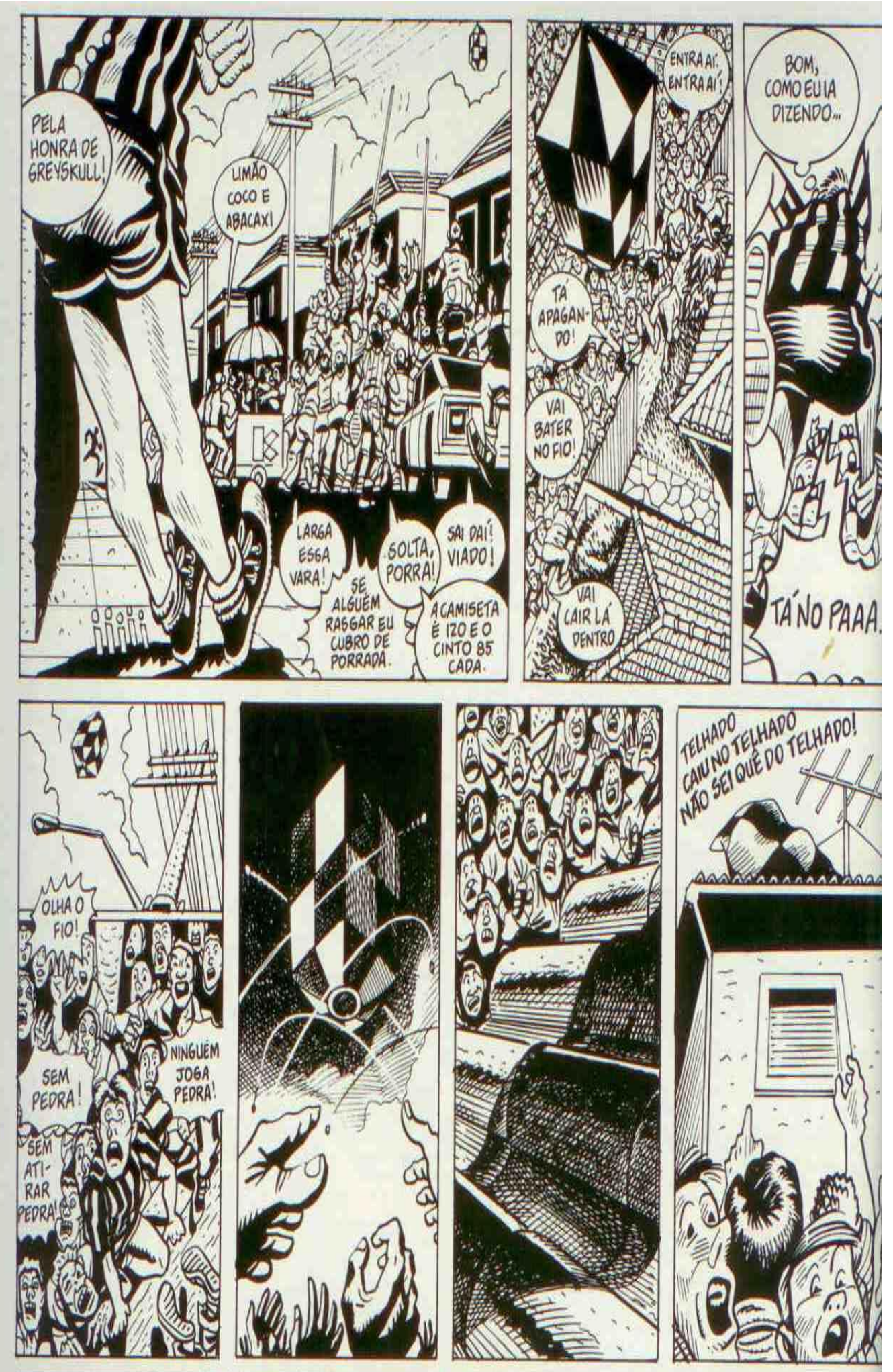

Figura 5 - Antissujeito no quinto quadrinho, quando o balão estava quase no "papo", caiu no telhado (nova parada). $\mathrm{O}$ antissujeito vai se densificando mais e, nesse momento, quase o objeto é destruído. 


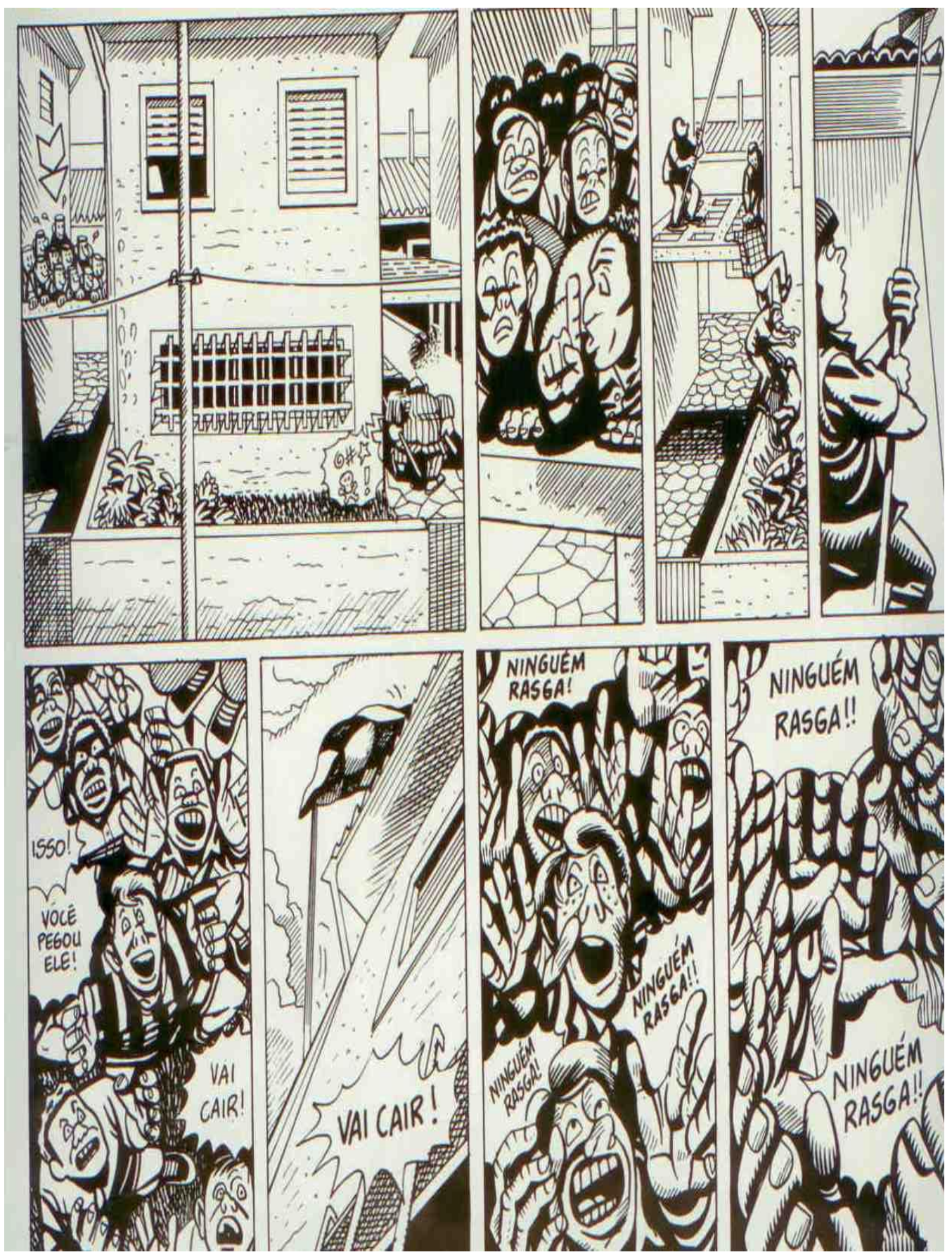

Figura 6 - No quarto quadrinho, vemos o menino com a varinha na mão prestes a conseguir o objeto. No entanto, os próprios sujeitos desejosos do objeto rasgam o balão. E, aqui, há o desmanche do objeto de desejo. Nesse caso, a densidade do antissujeito se tonifica. Há uma parada "crucial" no percurso dos sujeitos tomados pelo susto do rompimento do balão.

O valor remissivo emerge, portanto, como consequência de uma espécie de "lei rítmica que subordina o progresso narrativo à alternância, não necessariamente simétrica, dos períodos de distensão e contenção ou, em outros termos, de prevalência, ora dos valores emissivos, ora dos remissivos" (TATIT, 2010, p. 48).

O enunciador de "Futboil" subordina o progresso narrativo às alternâncias das concentrações (fazer remissivo) e difusões (fazer emissivo). Dessa forma, a dominância de um é a latência do outro. Daí o movimento narrativo oscilar entre distensões e contenções. A 
dominância tanto do fazer emissivo quanto do remissivo manifesta um movimento pendular de um fazer para o outro e vice-versa.

\section{Antissujeito átono no percurso da busca}

Em "Futboil", verificamos, nas figuras 2 a 6, pequenas interrupções na narrativa de meninos que correm atrás de um balão, que está caindo. Dessas pequenas paradas, podemos depreender a presença e, em alguns casos, a aproximação do antissujeito no campo de presença do sujeito. Quando em ação, o antissujeito pode ser eficaz ou ineficaz.

Se eficaz, por exemplo, imobiliza um percurso completamente. Sugerimos aqui o entendimento de um antissujeito tônico. Se ineficaz, o que acreditamos ser o caso de "Futboil" até o último quadrinho da figura 6, o antissujeito interrompe continuamente a narrativa por instantes, mas o sujeito retoma, logo em seguida, seu percurso. Neste último caso, o antissujeito constitui-se átono, visto ser facilmente superado; caso contrário, a corrida atrás do balão teria seu fim no começo da história.

Os termos "antissujeito tônico" e "antissujeito átono" servem-nos apenas para dividir as narrativas entre (1) aquelas em que as paradas duram, incomodando o enunciatário na espera de uma solução para a busca incessante do sujeito atrás de um objeto e, aqui, teríamos o caso de antissujeito tônico e (2) aquelas em que as paradas não duram, como é o exemplo do antissujeito átono em "Futboil". Os meninos sofrem, ao longo da narrativa, pequenas paradas em busca do balão para, finalmente, conquistar o objeto e destruí-lo no instante seguinte:

- $\quad$ Fazer emissivo: a narrativa corre -antissujeito átono/difusão/distanciamento

- $\quad$ Fazer remissivo: a narrativa para - antissujeito tônico/concentração/aproximação

- $\quad$ No último quadrinho, com a dissolução do objeto, a parada é terminativa, extingue-se o objeto, os sujeitos permanecem em choque $\rightarrow$ final da história. Para o prosseguimento da narrativa, seria necessária a substituição do objeto, o que configuraria nova história.

O enunciador de "Futboil", ao lado do narrador palhaço (que no nível narrativo é destinador), escolhe a dominância de valores emissivos em meio a algumas paradas para mostrar que a continuidade da corrida atrás de um balão não fracassou por causa das paradas (fazer remissivo) introduzidas pelo antissujeito átono, mas pela própria mão do sujeito que tanto queria seu objeto. O resultado de "Futboil" é o fracasso de um percurso em que a obstinação individual em conquistar tão ardentemente o objeto pode levar à destruição de um objeto, que é de valor coletivo.

No último quadrinho da HQ é que temos a revelação do "narrador palhaço" e o seu desprezo pelo jogo de Futboil (fenomenozinho tipicamente brasileiro). Considerando o esquema narrativo canônico, que leva em conta o percurso do destinador manipulador, o percurso do sujeito e o percurso do destinador julgador, no último quadrinho, figurativizado pelo ator palhaço, temos, num local predominantemente voltado para as relações comerciais e industriais (a história se passa no Brás, bairro caracterizado como berço da indústria paulista), pouco espaço para as relações lúdicas e artísticas. Dessa forma, por ser o último quadrinho tônico, surpreende o enunciatário. Metonimicamente, temos mãos que rasgam o balão e a cabeça de um palhaço no centro, afirmando "É isso aí amigos! E não esqueçam de perguntar ao freguês do lado qual o resultado do Futboil!", numa clara alusão à necessidade de distensão do cotidiano, diálogo intertextual com a brincadeira que o freguês faz ao garçom na mesa do bar, na música "Conversa de Botequim", de Noel Rosa.

A sanção do destinador julgador é de repulsão à atitude do sujeito, ou seja, os garotos não sabem brincar, porque destroem o objeto da brincadeira: o balão. $O$ maior antissujeito 
nessa $H Q$ é o próprio sujeito. Retomando o quadrinho 26 de "Futboil", verificamos tratar-se de um acróstico: "Fenomenozinho Urbano Tipicamente Brasileiro Observado In Loco". O diminutivo com carga semântica disfórica, juntamente com a duratividade de "tipicamente" e com a especificação do adjetivo "brasileiro", reforçam a isotopia do individualismo, em que cada um quer o balão para si, em detrimento de valores coletivos. Tanto o ludismo como o artístico exigem posturas sensíveis do sujeito em seu campo de presença.

Em "Futboil", a mesma competição do mundo cotidiano é transferida para a brincadeira com resultado catastrófico: ninguém fica com o objeto. Dessa forma, as continuidades promovidas pelo destinador e as descontinuidades promovidas pelo antissujeito são neutralizadas pelo sujeito em "Futboil", ou seja, o próprio sujeito transforma-se no final da HQ em antissujeito, quando estraçalha o objeto. Todos os antissujeitos do percurso, bem como as paradas, ficam mais atonizados se comparados ao sujeito que destrói o objeto de seu desejo.

Entrar em conjunção com o balão e conservá-lo seria admitir um sujeito competente (logo, um antissujeito não muito eficaz) para perceber e apreciar valores não pertencentes ao mundo utilitário. Em "Futboill", deparamos com certa incompetência do sujeito para entrar na posse de valores lúdicos e coletivos, da fantasia, próprios do mundo da arte, que passam à distância de valores marcados pelo automatismo do dia a dia desses sujeitos.

Para Huizinga (1996, p. 11-13), são características fundamentais do jogo e da arte: (a) ser livre, ser ele próprio liberdade; além disso, o jogo não é vida corrente nem real, mas evasão da vida real; (b) ser desinteressado, visto que não pertence à vida comum e se situa fora do mecanismo de satisfação "imediata" das necessidades e dos desejos; (c) distinguir-se da vida comum pelo lugar e duração que ocupa; daí seu isolamento e sua limitação; (d) possuir uma ordem específica e absoluta; ele cria ordem e é ordem, introduzindo na confusão da vida e na "imperfeição" do mundo uma "perfeição" temporária e limitada (cf. também GREIMAS, 2002, p. 88).

Mesmo depois do término do jogo, ele permanece como uma criação nova do espírito, um tesouro a ser conservado pela memória. A busca do balão, um folguedo juvenil, um jogo, é fratura que absorve os jogadores de maneira intensa e total, desprovida das ambições materiais do cotidiano; esse jogo é praticado dentro dos limites espaciais e temporais da HQ "Futboil".

Se os sujeitos não destruíssem o resultado do jogo, o balão, poderiam continuar com o grupo social formado e com o segredo do desfrute do encanto da fratura. Seriam sujeitos únicos da transgressão que se diferenciariam dos adultos, os mais velhos, que são regidos pela integração (o caso da D. Burda, por exemplo). Buscar o balão é lutar por alguma coisa, por um valor que não está na mediocridade do cotidiano automatizado. Finalmente, o jogo, a fratura, é dotado de um fim em si mesmo, que é acompanhado de um sentimento de tensão e de alegria e da consciência de ser diferente da vida cotidiana (HUIZINGA, 1996, p. 12, 16, 24, 33).

Ao final desse jogo, o enunciatário é surpreendido com o resultado frustrante: não ocorre a posse do balão, pois os próprios sujeitos, na ânsia da posse individual desse objeto, rasgam-no. A HQ, dessa forma, contempla dois momentos: (a) antes do aparecimento do balão: crianças jogam futebol; (b) surgimento do balão e abandono do futebol para a busca desenfreada do objeto fulgurante. Trocar o futebol pela busca do balão é abandonar um objeto desgastado pelo uso cotidiano para entrar em conjunção com uma novidade.

Todavia, superado o momento do deslumbramento, o sujeito (atores meninos) tende a retomar a vida vivida. Por isso, o último quadro é elucidador, quando o enunciatário pode 
verificar que a posse definitiva do balão não se dá, ou seja, o contato com o objeto é passageiro e leva o sujeito novamente à integração com os valores utilitários de seu cotidiano.

Finalmente, o palhaço, em "Futboil", ao se mostrar, revela as escolhas do enunciador: a emissividade eleita leva ao fracasso do sujeito: correm, correm, correm por nada, um efeito de humor. Nesse sentido, a destruição inesperada do balão leva o percurso do pervir a se transformar em sobrevir (ZILBERBERG, 2006, p. 223-233). No esquema, temos:

Densidade átona do antissujeito $\rightarrow \mathbf{O}$ balão esperado - ESPERA - (pervir $) \rightarrow$

Densidade tônica do antissujeito $\rightarrow$ Rompimento do balão - SURPRESA - (sobrevir)

Nesta HQ, temos, então, um antissujeito em alternância tensiva: de um lado, um antissujeito átono e latente superado durante a narrativa, que salpica o percurso do sujeito; de outro lado, um antissujeito tônico (o próprio sujeito), que esfacela o objeto conquistado. Este último tipo faz paradoxal e sincreticamente o papel actancial de antissujeito e de sujeito: eles mesmos querem, eles mesmos conseguem e eles mesmos rasgam o balão.

\section{Breve consideração final}

Quando em ação, pudemos observar que o antissujeito pode ser eficaz ou ineficaz. Se eficaz, imobiliza a continuidade da narrativa do sujeito, parcial ou até mesmo completamente. Sugerimos aqui, nesse caso, o entendimento de um antissujeito tônico. Se ineficaz, como vimos até quase o final de "Futboil", o antissujeito interrompe a narrativa por instantes: recuperado, o sujeito, logo em seguida, retoma seu percurso, ativando a continuidade da narrativa. Neste último caso, o antissujeito pode ser entendido como átono.

Concluímos que a bipartição entre "antissujeito tônico" e "antissujeito átono" nos serviu para depreender dois tipos de movimento: os de paradas durativas, imobilizando, então, o sujeito que busca incessantemente um objeto (caso de antissujeito tônico) e os de paradas de pouca duratividade, como é o exemplo do antissujeito átono, que pode ser superado muitas vezes em uma mesma narrativa.

\section{REFERÊNCIAS}

GÊ, L. Território de bravos. São Paulo: Editora 34, 1993.

GREIMAS. A. J. Da imperfeição. Tradução de Ana Claudia de Oliveira. São Paulo: Hacker, 2002.

HAUSER, A. História Social da arte e da literatura. São Paulo: Martins Fontes, 2003. HOUAISS, A.; VILLAR, M. de S. Dicionário Houaiss da língua portuguesa. Rio de Janeiro: Objetiva, 2001.

HUIZINGA, J. Homo ludens. Tradução de João Paulo Monteiro. São Paulo: Perspectiva, 1996.

LE ROBERT MICRO. Dictionnaire de la langue française. Rédaction dirigée par Alain Rey. Paris: Le Robert, 2006.

MERLEAU-PONTY, M. Fenomenologia da percepção. Tradução de Carlos Alberto Ribeiro de Moura. 3. ed. São Paulo: Martins Fontes, 2006.

PIETROFORTE, A. V. Análise textual da história em quadrinhos: uma abordagem semiótica da obra de Luiz Gê. São Paulo: Annablume: Fapesp, 2009. 
CASA, Vol.11 n.2, dezembro de 2013

PORTELA, J. C.; TOMASI, C. Cronopoiese e cronotrofia na história em quadrinhos. Estudos Semióticos, v. 8, n. 2, nov. 2012, p. 21-27.

TATIT, L. Semiótica à luz de Guimarães Rosa. São Paulo: Ateliê Editorial, 2010.

ZILBERBERG, C. Razão e poética do sentido. Tradução de Ivã Carlos Lopes, Luiz Tatit e Waldir Beividas. São Paulo: Edusp, 2006. 